\title{
José Nicolás de Azara contra Vicente Alcoverro: tres notas sobre un olvidado traductor de Horacio
}

\author{
Fernando Durán López \\ Universidad de Cádiz
}

Entre los años 1791 y 1801 se produjo por parte del jesuita expulso de Calatayud Vicente Alcoverro (1733-1801) un laborioso intento de traducir las obras completas de Horacio en verso castellano, acompañadas del original latino y de extensas notas y comentarios. De haber culminado su tarea, se trataría de la primera vez que se realizase tal hazaña en las letras españolas, una de las más ansiadas por los literatos de la época, que habían tomado al vate de Venusia como principal modelo clásico y paradigma de la perfección poética a la que ellos mismos aspiraban.

Alcoverro, un oscuro profesor de matemáticas, retórica y gramática en diferentes colegios jesuitas antes de la expulsión de 1767 y poeta satírico en castellano, se afanó durante años en obtener la protección del gobierno para ese proyecto desde su exilio en Génova y luego desde España, siempre con la mira puesta en que se le duplicase la exigua pensión de que vivía y, una vez de vuelta a su patria, en que se le concediese un empleo eclesiástico con una renta adecuada para sus aspiraciones. Probó con todos los sucesivos ministros de Estado desde Floridablanca hasta Ceballos, movió cuantas influencias pudo y reiteró sus solicitudes de manera incansable, cosechando fracaso tras fracaso. Sus traducciones fueron sometidas al dictamen de diferentes literatos civiles y eclesiásticos, tanto por parte del ministerio de Estado cuando quiso dedicar la obra al príncipe de Asturias y editarla en la Imprenta Real, como por parte de los censores del Consejo cuando probó a darla a luz en el establecimiento de Gabriel de Sancha, como por su propia iniciativa en busca de avalistas para su labor. 
Manuel de Lardizábal, José Vargas Ponce, Santos Díez, Manuel de Valbuena, Inocencio Martínez, Leandro Fernández de Moratín — y también Juan Andrés y otros jesuitas expulsos en Italia, si ha de creerse lo que dice Alcoverrofueron sucesivamente emitiendo opiniones más o menos extensas sobre el trabajo del traductor, por lo general opiniones negativas o bien matizados elogios que casi siempre pueden interpretarse también como críticas.

No es mi tarea en este sitio realizar el estudio detallado de este proyecto de traducción, porque a ello he dedicado recientemente un extenso trabajo al que remito a los lectores interesados en todos los pormenores ${ }^{1}$. Ahora deseo incorporar a esta historia un elemento nuevo, procedente de otro pequeño fondo documental que aporta la opinión de un nuevo censor, en este caso alguien tan importante y cualificado como el embajador de España ante la Santa Sede y reputadísimo humanista, el también aragonés José Nicolás de Azara. Mi objetivo es, por tanto, redondear lo que ya conocemos de la historia de esta accidentada traducción con estos documentos que la complementan. Los papeles que voy a reproducir sólo aparecen citados, que yo sepa, en una fuente bibliográfica, aunque de forma más bien incorrecta. Se trata del repertorio de autores jesuitas de Uriarte y Lecina, quienes dan una escueta noticia muy poco expresiva de sólo uno de los documentos que componen este expediente, el menos interesante de ellos ${ }^{2}$.

El Archivo de la Embajada de España ante la Santa Sede es un fondo riquísimo que se conserva hoy día en el Archivo del Ministerio de Asuntos Exteriores (AMAE) de Madrid. Allí se guarda toda la correspondencia oficial emitida por los embajadores en Roma. En concreto me interesan dos pequeños expe-

\footnotetext{
${ }^{1}$ Fernando Durán López, «El jesuita Vicente Alcoverro, Vargas Ponce, Moratín, Gabriel de Sancha y otros literatos dieciochescos: historia de una olvidada traducción de Horacio», Cuadernos de Ilustración y Romanticismo. Revista del Grupo de Estudios del Siglo xVIII (Universidad de Cádiz), núm. 7 (1999), págs. 139-199. En este trabajo se vacía el contenido de varios fondos documentales, el más importante —y el que guarda más relación con el presente artículo— conservado en el Archivo Histórico Nacional, Estado, leg. 3234, exp. 16. Los otros documentos son: el expediente de impresión abierto por Gabriel de Sancha para la publicación de las odas (AHN, Consejos, leg. 5560, exp. 97), la breve correspondencia entre Alcoverro y Vargas Ponce (Real Academia de la Historia, Colección Vargas Ponce 10, sign. 9-4183, carpeta T); los manuscritos conservados de la traducción de las sátiras horacianas por Alcoverro (Biblioteca Nacional, sign. ms. 3120, y Biblioteca de Menéndez Pelayo, sign. ms. 95), y algunos papeles menores. En el artículo se extracta toda la documentación, se reproducen por extenso los más importantes y se incluye un amplio apéndice con algunos de ellos.

${ }^{2}$ José Eugenio de Uriarte y Mariano Lecina, Biblioteca de escritores de la Compañía de Jesús pertenecientes a la antigua asistencia de España desde sus orígenes hasta el año 1733..., Madrid, Viuda de López del Horno, 1925, t. I, págs. 93a-95a, s. v. «Alcoverro». En la letra Aa de esa entrada se cita una «Carta al conde de la Cañada sobre su traducción de Horacio.— Génova 26 de Octubre de 1794. (Arch. de la Embaj. de España en Roma.)» (pág. 94b). En mi anterior artículo cité de pasada esta fuente (véase art. cit., nota 45), que por entonces no había podido consultar todavía personalmente.
} 
dientes del AMAE, donde se registra el intercambio de oficios entre José Nicolás de Azara y el Conde de Floridablanca, primero, y el Conde de la Cañada ${ }^{3}$, después, a propósito de las insistentes peticiones al gobierno de Vicente Alcoverro ${ }^{4}$.

La documentación del AMAE comienza en un punto anterior al papel más antiguo que se conserva en el expediente sobre Alcoverro de la sección de Estado del AHN. Éste se abre actualmente con el documento núm. 2, una carta autógrafa del jesuita aragonés a Godoy de fecha 12 de Abril de 1793 (en el expediente falta el núm. 1, pero éste no pudo ser de fecha muy anterior). Los papeles del AMAE corresponden, por tanto, a las primeras gestiones de Alcoverro ante el gobierno, antes incluso de iniciar su proyecto horaciano. Sabíamos por el doc. 8 del citado legajo del $\mathrm{AHN}^{5}$, un memorial de agosto de 1799, que en 1791 se expuso en Génova una estatua del Rey de España que iba a ser llevada a Ceuta. Con ese motivo Alcoverro compuso algunos poemas, entre ellos según dice una traducción de la Oda I, 3, de Horacio. El primer papel del AMAE supone un testimonio directo de ese hecho que hasta ahora sólo conocíamos indirectamente: en efecto, el 21 de Junio de 1791 el Conde de Floridablanca —el ministro de Estado en ese momento — se dirige a su embajador en Roma José Nicolás de Azara para que socorra al ex jesuita Alcoverro si cree que lo merece. Éste es el primer documento que voy a reproducir aquí, en éste como en todos los demás casos modernizando la ortografía y la puntuación y desarrollando algunas de las abreviaturas:

Legajo 240. Reales Órdenes a Azara, 1791. Doc. 71: Real Orden del Conde de Floridablanca a José Nicolás de Azara, fechada en Aranjuez, 21-VI-1791. En

\footnotetext{
${ }^{3}$ Juan Acedo Rico y Rodríguez (1726-h. 1821), extremeño, alto funcionario de la administración pública con Carlos III y Carlos IV, como consejero de Estado y de Hacienda, pero sobre todo como decano del Consejo de Castilla y luego gobernador del mismo tras la muerte del Conde de Cifuentes, cargo que ocupaba cuando tienen lugar los hechos que aquí se cuentan. En 1789 se le concedió el título de Conde de la Cañada.

${ }^{4}$ Se trata del legajo 240 del fondo romano, documento 71; y del legajo 362, expediente 15 (que consta de siete piezas). Su contenido puede verse en el índice del Archivo de la Embajada ante la Santa Sede, aunque con algunas inexactitudes. En principio, aquí se conservan los originales de los papeles remitidos desde Madrid y los borradores de los que Azara envió al gobierno, mientras que en el AHN tendrían que conservarse los originales de Azara y las minutas de los oficios de Floridablanca, que era el ministro de Estado, y de Cañada, que era gobernador del Consejo. No obstante, el fondo del AMAE no se corresponde en ningún momento con el legajo de AHN (Estado) donde figura el expediente de Alcoverro, en el que no se cita nunca a Azara ni a Cañada, y no se alude a los papeles del AMAE. Esto hace suponer que debe de existir en AHN (bien en la sección de Estado, bien en la de Consejos) otro legajo con documentación relacionada con este asunto, que tal vez más adelante pueda ser localizado y ofrezca nuevas pistas, como por ejemplo, copias de los poemas del jesuita aragonés.

${ }^{5}$ A partir de aquí, cuando hable de papeles del AHN, me referiré siempre al expediente de la sección de Estado, leg. 3234, exp. 16, salvo que indique expresamente lo contrario.
} 
el sobrescrito dice: Sobre ciertos sonetos compuestos por el ex-jesuita Don Vicente Alcoverro, residente en Génova, en alabanza de la estatua del Rey trabajada en aquella ciudad:

\section{Excmo. Señor.}

El ex-jesuita D. Vicente Alcoverro, residente en Génova, ha remitido los adjuntos sonetos manuscritos que ha compuesto a la estatua del Rey, que en aquella capital ha trabajado el escultor Ravasqui, para colocarse sobre la puerta de la ciudad de Ceuta, y habiendo hecho presente a Su Majestad este trabajo literario, quiere que en su vista socorra V. E. a su autor, si lo merece. Lo que de su Real Orden participo a V. E. para su inteligencia y cumplimiento. Dios guarde a V. E. muchos años. Aranjuez, 21 de Junio de 1791.

En esa orden no se alude a ninguna oda traducida, sino sólo a ciertos sonetos laudatorios en castellano, que parece ser lo único que tuvo ante sí Azara, de forma que no se sabe bien si en realidad la tal oda formaba parte de lo que Alcoverro remitió en 1791 a Madrid o si añadió más adelante esa otra pieza por conveniencia. En cualquier caso, Azara fue inclemente con su paisano: después de puntualizar que los ex jesuitas de Génova no dependen de su embajada, hace un juicio demoledor sobre la calidad de los versos de Alcoverro.

Legajo 362: Oficios de la Embajada, 1791. (Registro de Despachos de Azara.) Exp. 15: «Sobre el ex-jesuita D. Vicente Alcoverro». Doc. 1: Minuta de la respuesta de Azara a Floridablanca ${ }^{6}$.

En 27 de Julio de 1791

al Señor Conde de Floridablanca.

Excmo. Señor:

Muy señor mío: con carta de 21 de Junio me remitió V. E. ciertos sonetos compuestos por el ex-jesuita D. Vicente Alcoverro en alabanza de la estatua del Rey que se ha trabajado en Génova para colocar sobre la puerta de Ceuta, y me manda V. E. que socorra al autor, si creo que lo merece.

Como dicho jesuita reside en Génova, no toca a mí el socorrerle, sino a D. Juan Cornejo ${ }^{7}$, de quien depende aquel departamento. Esto supuesto, no debo de hacer

\footnotetext{
${ }^{6}$ En realidad, este papel está fuera de su sitio: debería estar en el registro cronológico de la correspondencia de Azara con Floridablanca, donde lo sitúa el índice y de donde falta: alguien lo ha colocado aquí, por coherencia con lo que sigue, que es un expediente separado.

${ }^{7}$ Juan Cornejo fue ministro español ante la República de Génova durante muchos años en la época en que Alcoverro vivió en esa ciudad.
} 
de juez del mérito de dichas composiciones, pero no puedo menos de acordar a V. E. lo que sabe tan bien como yo, que en Italia es arte vieja y despreciable la de hacer sonetos para pedir limosna y que estas composiciones van a tan vil precio, que si se pagasen a peseta la docena se enriquecerían muchos de estos poetas. El ex-jesuita Alcoverro parece que ha tomado bien la lección del país, pues dirige todas sus poesías a pedir un socorro. Creo muy bien que lo merecerá por otras cualidades, pero por la de poeta, y por sus versos, que devuelvo a V. E., yo no le daría [palabra ilegible: ¿tal...? $\left.{ }^{8}\right]$, ni me cuidaría mucho de que me alabase en sus sonetos. Quedo etc.

Sin duda, la Secretaría de Estado no desconocía el hecho de que el solicitante, al residir en Génova, no caía bajo la jurisdicción de la legación en los Estados Pontificios: tal vez haya que interpretar el que se le remitiera esa comisión a Azara como el deseo de que fuese él, por su prestigio como sabio humanista, quien dictaminase la calidad de los trabajos presentados. Sea como sea, el gobierno no hizo caso de Azara: por lo que sabemos por los papeles del AHN, Alcoverro recibió una recompensa de cien ducados y se le animó —o así lo entendió él o quiere hacerlo creer para mejor fundamentar sus posteriores requerimientos de ayuda - a que continuase su traducción de Horacio9.

El siguiente paso de Alcoverro es reiterar su petición esencial, la duplicación del dinero que tiene asignado como pensión, aprovechándose del supuesto encargo que se le ha hecho de traducir a Horacio en verso castellano. Según los documentos del AMAE, lo hace el día 30 de Agosto de 1792, es decir, todavía en fecha anterior a los papeles conservados en el AHN, y se dirige al Conde de la Cañada, lo que indica que Alcoverro había decidido probar fortuna ante otro poderoso órgano de la administración, el Consejo de Castilla, donde tal vez confiaba tener más eco que en el ministerio de Estado. En esa carta anuncia que tiene ya traducidos dos tomos de las odas horacianas con notas y revisados por algunos literatos. No envía ninguna muestra, se limita a informar de su trabajo, a pedir instrucciones y, por supuesto, a explicitar su deseo de aumento de la asignación. El Consejo no parece haberse tomado la molestia de contestar ni de realizar gestión alguna hasta el 30 de Abril de 1793, en que el Conde de la Cañada pasa a Azara la representación de Alcoverro de agosto del año anterior para que diga si tiene noticia de la obra y qué le parece lo que pide el exjesuita. Azara contesta desde Roma en julio de 1793, con su habitual contundencia:

\footnotetext{
${ }^{8}$ Creo que puede tratarse de «talega» o «talego», con el mismo sentido monetario que en el lenguaje actual.

${ }^{9}$ El documento donde se le comunica la recompensa y presuntamente se le anima a proseguir su traducción no se halla en ninguno de los legajos que he visto sobre esta cuestión.
} 
Legajo 362, exp.15 (ya citado). Doc. 2: Oficio del Conde de la Cañada a Azara.

\section{Excmo. Señor.}

Dirijo a V. E. la adjunta copia de la representación que me ha hecho el exjesuita sacerdote D. Vicente Alcoverro, a fin de que se sirva V. E. decirme si tiene noticia de la obra que en ella se expresa, y en este caso lo que se ofreciere y pareciere acerca de la solicitud de dicho ex-jesuita.

Dios guarde a V. E. muchos años. Madrid, 30 de Abril de 1793.

El Conde de la Cañada.

\section{Doc. 3: Copia de la antecitada representación.}

\section{Excmo. Señor:}

En agradecimiento a la recompensa que me fue hecha por la superioridad del año pasado a motivo de algunas poesías que remití en alabanza del Rey Nuestro Señor, y entre ellas una traducción literal en verso rimado de la Ode $3^{\text {a }}$ de Horacio, aplicándola al viaje de la Real Estatua conducida a Ceuta, y por obedecer a la insinuación superior de continuar semejantes traducciones, desde luego me apliqué con el tesón que pide un autor tan difícil como Horacio a perfeccionar y a trabajar de nuevo lo que me faltaba para formar una traducción entera de las obras de aquel sublime autor arreglada al dicho método.

Dos tomos tengo ya enteramente perfeccionados e ilustrados con notas, que he hecho primero rever a algunos de nuestros literatos, de quienes han merecido la aprobación, no juzgándolas desmerecedora[s] de la luz pública.

Un preciso deber me obliga [a] dar parte a V. E. de esta mi obra, la cual dejo enteramente a su disposición, deseando me insinúe el uso que debo hacer de ella, y suplicando al mismo tiempo a V. E. interponer sus benéficos influjos con el Rey Nuestro Señor, para la gracia de doble pensión, que ya desde el año pasado pedí a título de Regio Profesor que fui de Matemáticas en el de Cordellas, con real pensión, a fin de facilitarme los medios para la conclusión de mi obra, gracia de que gozan ya mis compañeros comprofesores. Me encomiendo a la protección de V. E., cuya vida guarde Dios muchos años. Génova, 30 Agosto de 1792. = B. L. M. de V. E. su más rendido servidor y capellán, D. Vicente Alcoverro, sacerdote. = Excmo. Sr. Conde de la Cañada.

Doc. 4: Minuta de la respuesta de Azara al Conde de la Cañada.

Roma, 31 Julio 93

Al Conde de la Cañada 
Excmo. Señor.

Muy señor mío, en carta de 30 de abril me remitió V. E. el memorial del exjesuita D. Vicente Alcoverro, en que pide ser premiado por haber hecho una traducción de Horacio en castellano, y alega además el mérito de ciertas poesías que compuso en alabanza de una estatua del Rey padre, que está en gloria ${ }^{10}$, y me pide V. E. que le diga mi parecer sobre su pretensión.

Dos años hace que este mismo sujeto recurrió al Conde de Floridablanca con semejante pretensión, y habiéndome pedido informe dicho ministro, se lo di muy contrario a los deseos del [¿̨remitente?], como V. E. podrá ver por la copia que le incluyo de mi carta. Sin embargo de ella, parece que obtuvo alguna gratificación, aunque no por mi mano, porque es del departamento de Génova.

Entonces no se trataba sino de sus malos versos, pero como ahora añade que ha traducido a Horacio, debo decir a V. E. que no conozco su traducción, y así no puedo juzgar de ella, pero en general debo decir que la empresa de traducir un autor como Horacio es la más ardua de la literatura, que mil la han probado en varias lenguas, y ninguno ha conseguido alabanza, y por fin, que por lo que conozco de Alcoverro le creo incapaz de traducir bien ni mal a Horacio, pues ignora no sólo la lengua latina, sino la española, y si se le ha de dar algún premio, sea porque no publique ninguna obra suya.

Quedo a la [ilegible la despedida formulística que sigue].

Las razones de la tardanza en reaccionar del gobernador del Consejo nos son desconocidas, pero tal vez se tengan que relacionar con el hecho de que Alcoverro inició otras gestiones ante la Secretaría de Estado, que se documentan en el citado expediente del AHN. Ya que su memorial de Agosto no tuvo respuesta, el bilbilitano se dirige de nuevo a la corte madrileña el 12 de Abril de 1793, esta vez escribiendo directamente a la persona del ministro de Estado, que era entonces Godoy, y acompañando su petición de ayuda con una muestra de su traducción, un cuaderno con dieciséis de las odas de Horacio traducidas. Es en ese punto cuando comienza el expediente del AHN. La coincidencia de fechas no parece un azar: el 12 de Abril escribe Alcoverro y el 30 de Abril el Conde de la Cañada reacciona a una petición del pasado Agosto pidiendo informe a Azara. Se puede sospechar que Alcoverro tal vez volviera a escribir al Consejo al mismo tiempo que a la Secretaría de Estado, o que ésta pusiera sobre aviso al Conde de la Cañada. En los papeles conservados en el AHN no se hace mención alguna ni de la representación de Agosto de 1792, ni de José Nicolás de Azara, ni del Conde de la Cañada. Con gestiones abiertas a la vez ante dos impor-

${ }^{10}$ Azara se equivoca: la estatua en cuestión no era de Carlos III, sino del reinante Carlos IV. 
tantes departamentos gubernamentales, el resultado fue, sin embargo, negativo por ambos lados.

Como resultas de la petición de Abril de 1793, Godoy también remitió el cuaderno con las odas a la censura de la Real Academia Española, en concreto el día 11 de Mayo de 1793, y el censor académico, Lardizábal, contestó en Junio que el trabajo del traductor le parecía malo e indigno de publicarse con protección oficial. Al mismo tiempo, el gobernador del Consejo remitía a Azara la petición anterior, de Agosto del 92. Tanto si las dos censuras se encargaron de forma independiente o coordinada, el resultado fue similar: se rechazaba la petición de Alcoverro, y Azara lo hizo de forma todavía más agria que Lardizábal, lo que resalta especialmente porque estaba juzgando un trabajo que no había leído y negando la capacidad de un traductor del que, en realidad, sólo dice conocer algunos poemas de circunstancias.

La historia continúa, aunque para la parte restante el fondo del AMAE no aporta ya novedades sustanciales. No sabemos si el Consejo de Castilla contestó o no a Alcoverro, ni cómo lo hizo. La Secretaría de Estado, por su parte, se olvidó o no se tomó la molestia de comunicar al interesado el rechazo de su solicitud y dejó que el aragonés se impacientara en Génova. En Septiembre de 1793, cinco meses después de su última gestión, el jesuita conoció a José Vargas Ponce, que estaba de paso en la capital ligur con la flota española que guerreaba contra la República Francesa; pensó que el escritor gaditano podía mover hilos en Madrid y le pidió su mediación, dándole el manuscrito del tomo I de las odas completo para que le mostrase su parecer sobre él, que fue muy negativo. Pero Vargas también le dijo que, ya que la guerra interrumpía los correos, era mejor que volviese a escribir a Madrid enviando el citado tomo, por si su envío anterior se hubiera extraviado. Alcoverro así lo hizo ese mismo mes de Septiembre. Tampoco tuvo respuesta de Madrid y en Marzo de 1794 vuelve a dirigirse a la Secretaría de Estado pidiendo una resolución favorable o negativa: Godoy pide que le pongan en antecedentes y ordena que, dadas las censuras negativas, se pase el manuscrito a Gabriel de Sancha, como había indicado Alcoverro para el caso de que se rechazase su solicitud. En Abril de 1794 se da por cerrado el asunto.

A partir de aquí se desarrolla un nuevo proceso administrativo de imprenta que se conserva en la sección de Consejos del AHN, abierto por Gabriel de Sancha para imprimir por su cuenta la traducción. Este proceso se desarrolla entre Septiembre de 1795 y Noviembre de 1798, y se salda con la licencia de publicación, aunque no llegó a editarse el libro. Durante esos meses no hay ningún papel en el legajo de Estado del AHN y, a juzgar por esto, parece que Alcoverro había desistido de sus gestiones hasta el gobierno, que sólo reanudaría en 
Agosto de 1799. Sin embargo, gracias a la documentación del AMAE, sabemos ahora que el ex-jesuita volvió a realizar gestiones ante el Consejo en ese periodo de tiempo, concretamente en Octubre de 1794. Ahora se limita a reiterar su petición de que, en virtud de sus trabajos literarios — que se cuida de decir que habían sido reprobados-, se le doble la pensión, objeto continuo de sus aspiraciones. El Conde de la Cañada remite en Diciembre de 1794 la solicitud a Azara, que, con visible desgana repite su anterior informe sin añadir nada nuevo. Éstos son los últimos documentos del AMAE que se ocupan de este asunto:

Legajo 362, exp.15 (ya citado). Doc. 5: Oficio del Conde de la Cañada a Azara.

Excmo. Señor:

Remito a V. E. la adjunta copia de la representación que ha hecho el ex-jesuita sacerdote Don Vicente Alcoverro, residente en Génova, para que en su vista informe V. E. lo que resulte y se le ofrezca.

Dios guarde a V. E. muchos años. Madrid, 23 de Diciembre de 1794.

El Conde de la Cañada.

Doc. 6: Copia de la antecitada representación ${ }^{11}$.

Excmo. Señor.

Señor. El sacerdote D. Vicente Alcoverro, de la extinguida Compañía, habitante en Génova, con el más profundo respeto, humildemente expone: que en los últimos años precedentes a la expulsión se hallaba ejerciendo el empleo de Regio Profesor de Matemáticas en el Real Colegio de Cordellas en la ciudad de Barcelona; que a más de esto, desde que está en la Italia ha compuesto diferentes obras literarias, y entre ellas para uso de la juventud española ha traducido en verso las obras de Horacio, de cuya impresión actualmente se trata. Por cuyos motivos:

A V. E. suplica rendidamente la gracia de la doble pensión concedida a los otros Regios Profesores de Matemáticas, y que se suele conceder a aquellos sujetos que se han dedicado a la composición de algunas obras literarias, gracia que espera de V. E., que Dios guarde muchos años. Génova, 26 de octubre de 1794. = B. L. M. de V. E. su más rendido servidor y capellán. = D. Vicente Alcoverro.

${ }^{11}$ Éste es el único documento del AMAE que citan Uriarte y Lecina (op. cit.). 
Doc. 7: Minuta de la respuesta de Azara al Conde de la Cañada.

Al Conde de la Cañada en 11 de febrero de 1795.

En carta de 23 de Diciembre me incluyó V. E. copia de una representación del ex-jesuita sacerdote Don Vicente Alcoverro, residente en Génova, encargándome le informe de lo que se me ofrezca.

Me es fácil de cumplir el mandato de V. E., no siendo la primera vez que he practicado este mismo oficio, y así le remito una copia de lo que escribí a V. E. en Julio de 1793 respondiendo a otro igual encargo que ahora me hace, sin ofrecérseme que quitar ni añadir a lo que tuve entonces la honra de participar a V. E. Quedo, etc.

El resto de la historia de Alcoverro y su traducción ya no registra ninguna intervención de José Nicolás de Azara, pero continúa hasta 1801 con la muerte del poeta bilbilitano, en términos que relaté con detalle en mi citado artículo. Ya sólo me queda, para terminar, valorar la breve intervención que tuvo el embajador Azara en este asunto, que creo que es el principal interés de los documentos que presento.

La vitriólica reacción del embajador ante las peticiones del jesuita es buena muestra de algunos de los rasgos de su carácter, como la profunda inquina que le despertaban los jesuitas y su desprecio ante los malos escritores. Azara no tuvo reparos en socorrer a los expulsos que estaban bajo su jurisdicción, e incluso colaboró de buena gana con los sabios de la Compañía a quienes respetaba intelectualmente, como Esteban de Arteaga, con quien en esos mismos años de las propuestas de Alcoverro había llevado a cabo un magno proyecto de edición de las obras de Horacio en la imprenta parmesana de Giambattista Bodoni, la misma en que años después Alcoverro planeó imprimir su traducción. Así pues, Azara estaba plenamente capacitado para valorar la importancia del proyecto horaciano, por sus propias preocupaciones acerca de su admirado poeta latino, pero no creía a Alcoverro en disposición de hacerlo ni tampoco querría fomentar las aspiraciones de posibles rivales en esas materias humanistas.

Con todo, lo más revelador es, a mi juicio, la soltura con que Azara maneja la cuestión para desembarazarse en lo que dura un suspiro de una fastidiosa comisión: con unas pocas líneas más bien demoledoras emite un dictamen completo sobre la valía literaria de una persona a la que, según parece, no conocía. Desde luego lo hace con una gracia que no es habitual en los escritos administrativos ${ }^{12}$.

\footnotetext{
${ }^{12}$ Deseo agradecer su ayuda a María Dolores Gimeno Puyol, investigadora que realiza una tesis sobre la correspondencia de Azara en sus años romanos y se ha tomado la molestia de comprobar para mí que no se cita a Alcoverro en las casi quinientas cartas que ha recogido, además de ofrecerme valiosas sugerencias sobre la personalidad del diplomático aragonés.
} 